\title{
Recommendations for hypofractionated whole-breast irradiation
}

\begin{abstract}
Author: SBRT, Brazilian Society of Radiotherapy
Participants: (DD Nilceana Maya Aires Freitas', Arthur Accioly Rosa², (ID Gustavo Nader Marta,4, Samir Abdalla Hanna ${ }^{4}$, Rodrigo de Morais Hanriot ${ }^{5}$, Allisson Bruno Barcelos Borges ${ }^{6}$, Guilherme Rocha Melo Gondim ${ }^{5,7}$, Antonio Cassio Assis Pellizzon, Igor Moreira Veras ${ }^{8}$, Wilson José de Almeida Júnior ${ }^{9}$, Claudia Regina Scaramello Hadlich Willis Fernandez ${ }^{10}$, Eronides Salustiano Batalha Filho ${ }^{11}$, Marcus Simões Castilho ${ }^{12}$, Felipe Quintino Kuhnen ${ }^{13}$, Rosa Maria Xavier Faria Najas ${ }^{14}$, Renato José Affonso Júnior ${ }^{6}$, André Campana Correia Leite ${ }^{15}$, Homero Lavieri Martins Ribeiro ${ }^{16}$, (iD Ruffo Freitas-Junior ${ }^{17}$, (D) Harley Francisco de Oliveira ${ }^{18}$.

Final version: July 8, 2018

1. Radiotherapy Department of the Araújo Jorge Hospital of the Góias State Association Against Cancer, Goiânia/GO, Brasil. 2. Radiotherapy Department of the Bahia State Portuguese Hospital, Salvador/BA and President of the Brazilian Radiotherapy Society (SBRT), São Paulo/SP, Brasil. 3. Department of Radiology and Oncology, Division of Radiation Oncology, Instituto do Câncer do Estado de São Paulo (ICESP), Faculdade de Medicina da Universidade de São Paulo, São Paulo,

Brazil. 4. Department of Radiation Oncology, Hospital Sírio-Libanês, São Paulo, Brazil 5. Radiotherapy Department of the Oswaldo Cruz German Hospital, São Paulo/SP, Brasil. 6. Radiotherapy Department, Barretos Cancer Hospital, Barretos/SP, Brasil. 7. Radiotherapy Department of the AC Camargo Hospital, São Paulo/ SP, Brasil. 8. Radiotherapy Department of the Regional Integrated Oncology Center, Fortaleza-CE. 9. Radiotherapy Department of the Moinhos dos Ventos Hospital, Porto Alegre-RS. 10. Radiotherapy Service of the José Alencar Gomes da Silva National Cancer Institute, Rio de Janeiro/RJ, Brasil. 11. Radiotherapy Department of the Brasilia State University Hospital and representative of the Ministry of Health, Brasili/DF, Brasil. 12. Radiotherapy Department of the Felicio Rocho Hospital, Belo Horizonte/MG, Brasil. 13. Radiotherapy Department of the Charity Hospital of Florianópolis, Florianópolis/SC, Brasil. 14. Radiotherapy Department of the Rio Grande do Norte State League Against Cancer, Natal/RN, Brasil. 15. Department of Radiation Oncology, Fundação Centro de Controle de Oncologia Manaus- AM. 17. Mastology Program of the Goias Federal University, Goiânia-GO and representative of the Brazilian Mastology Society, São Paulo/SP, Brasil. 18. Centro de Tratamento em Radio-Oncologia (CTR) and Ribeirão Preto Medical School (FMRP) da Universidade de São Paulo (USP) - Ribeirão Preto/SP; Hospital Márcio Cunha (HMC) - Ipatinga/MG, Brasil.
\end{abstract}

\section{SUMMARY}

This recommendation consensus for hypofractionated whole-breast radiotherapy (RT) was organized by the Brazilian Society of Radiotherapy (SBRT) considering the optimal scenario for indication and safety in the technology applied. All controversies and contraindication matters (hypofractionated RT in patients who underwent chemotherapy [CT], hypofractionated RT in lymphatic drainage, hypofractionated RT after mastectomy with or without immediate reconstruction, boost during surgery, hypofractionated RT in patients under 50 years old, hypofractionated RT in large breasts, hypofractionated RT in histology of carcinoma in situ [DCIS]) was discussed during a meeting in person, and a consensus was reached when there was an agreement of at least 75\% among panel members. The grade for recommendation was also suggested according to the level of scientific evidence available, qualified as weak, medium, or strong. Thus, this consensus will aid Brazilian radiotherapy experts regarding indications and particularities of this technique as a viable and safe alternative for the national reality.

DATE OF SUBMISSION: 06-Jul-2018

DATE OF ACCEPTANCE: 08-Jul-2018

CORRESPONDING AUTHOR: Harley Francisco de Oliveira

Brazilian Society of Radiotherapy -SBRT - Pça. Oswaldo Cruz, 124 - cj. 52 - 5o andar

Paraíso - São Paulo - SP - CEP 04004-070 - Phone/Fax: (11) 3262-3976

E-mail: sbradioterapia@sbradioterapia.com.br, sbradioterapia@uol.com.br 


\section{INTRODUCTION}

Breast cancer represents around 29.5\% of all cancer types in Brazil, and it is the most prevalent type amongst women. It is estimated there were 59,700 new cases in the country in $2018^{1}$, around 56 cases for every 100,000 women.

Radiotherapy (RT) is an essential part of Breast cancer treatment during early stages, with proved benefits of survival after conservative surgery ${ }^{2}$. The conventional fractionation (1.8-2 Gy per fraction) has been used as the standard over the last decades, with a total dose of 50-50.4 Gy over 25-28 sections, distributed over 5 consecutive weeks.

Hypofractionated radiotherapy is an RT technique in which the total dose is administered over a shorter time range with fractionated doses that are higher than the conventional ones. The scientific evidence for its use is established by prospective and randomized studies, including a considerable number of patients submitted to the conventional treatment for breast cancer, with comparable safety, effectiveness, local control, and survival observed on conventional treatment. It is a technique widely used in several countries $^{3,4,5}$.

The implementation of the whole-breast hypofractionated RT in the clinical routine was larger amongst academics than in community hospitals ${ }^{6}$. Variations in indication, considering anatomical aspects, planning parameters, technical and prognostic factors had a significant influence in that scenario. Recent recommendations allowed for a larger scope of indications for the use of whole-breast hypofractionated radiotherapy so that the slightest variations in medical decisions could intervene in treatment individualization ${ }^{6}$.

Brazil faces the same difficulty to include hypofractionated radiotherapy in current clinical practice, whether it is for funding reasons or technical matters; so far, it has only been implemented in reference centers. In the current Brazilian reality, the lack of RT equipment has caused difficulty of access, long waiting lines, and delays for beginning treatment, all of which can compromise the oncology effectiveness $\mathbf{7 , 8 , 9}$. The reduction in RT time could allow for an increased in installed capacity and, consequently, expand the access:

This article aims to report the consensus for recommendation of the Brazilian Society of Radiotherapy (SBRT) for the use of whole-breast hypofractionated RT.

\section{METHODOLOGY}

A meeting was organized to take place in the city of São Paulo on March 3rd, 2018, for which were invited the leading members of SBRT with renowned expertise and dedicated to the treatment of breast cancer. Representatives of some of the main reference centers for RT from each of the country's regions were invited, both from the Public Health System (SUS) as well as from the supplementary healthcare network. The panel was attended by 18 radio-oncologists, a physician representative of the Brazilian Association of Medical Physics (ABFM) and a mastologist representing the Brazilian Society of Mastology (BSM), the last two chosen as ad hoc consultants. Only the radio-oncologists had voting rights.

The literature available on the subject was reviewed, presented and discussed during plenary. Questions were raised regarding the indications and safety of whole-breast hypofractionated RT in different clinical contexts ${ }^{10}$, which were put to the vote of panel members according to the Delphi Method ${ }^{11}$.

There were three possible answers to the questions: agree, disagree, abstains. The consensus was reached when there was an agreement amongst at least $75 \%$ of the panel members. The grade for recommendation was also suggested according to the level of scientific evidence available, qualified as weak, medium, or strong, as follows.

\section{Level of scientific evidence:}

Strong Level - Data obtained from multiple randomized studies of good size, concordant and/or of a robust meta-analysis of randomized controlled trials.

Medium Level - Data obtained from a less robust meta-analysis, from a single randomized trial or from non-randomized trials (observational).

Weak Level - Data obtained from experts' consensual opinions.

For organization purposes, the meeting was divided into three main discussion section:

Section I - Who is the ideal patient for wholebreast hypofractionated RT?

Section II - Controversies and contraindications

All controversial issues were discussed in section II. Since there is still no strong evidence in the current literature on certain clinical contexts, particularities and subgroup analyses were conducted for consensus on the following subjects: Hypofrac- 
tionated RT in patients who underwent chemotherapy (CT), hypofractionated RT in lymphatic drainage, hypofractionated RT after mastectomy with or without immediate reconstruction, boost use during surgery, hypofractionated RT in patients under 50 years old, hypofractionated RT in large breasts, hypofractionated RT in histology of carcinoma in situ (DCIS).

Section III - Safety in the technology applied

\section{RESULTS}

Section I - Optimal scenario for the indication of whole-breast hypofractionated RT

The SBRT consensus considered hypofractionated RT to be safe and effective for women who meet all the following clinical criteria:

- Have underwent conservative treatment for breast cancer;

- Are over 50 years old.

- Have invasive carcinoma of no special type, grades I and II;

- Have clinical stages T1 and T2;

- Have negative axillary lymph nodes;

- There is no particularity regarding the laterality of the affected breast;

- There is no restriction regarding the immunohistological profile (patients with positive hormone receptors, HER2 super-expressed or triple negative).

\begin{tabular}{|l|l|}
\hline Level of agreement & Level of evidence \\
\hline $100 \%$ & Strong \\
\hline
\end{tabular}

\section{Dose and fractionation:}

The models of moderate fractionation of $42.5 \mathrm{~Gy}$ in 16 fractions and of $40 \mathrm{~Gy}$ in 15 fractions are equally safe and effective.

\begin{tabular}{|l|l|}
\hline Level of agreement & Level of evidence \\
\hline $100 \%$ & Strong \\
\hline
\end{tabular}

Comments: The hypofractionated models are those that use a dose above $2 \mathrm{~Gy} /$ fraction. The fractionation models used in the Start $\mathrm{B}^{12}$ studies of 40 Gy in 15 fractions and in the Canadian study ${ }^{4}$ of 42.5 Gy in 16 fractions present consistent results regarding late toxicity, survival free of locoregional recurrence, and quality of life with 10-year average follow-up ${ }^{4}$

\section{Section II - Areas of controversy and} contraindications

Mastectomy and reconstruction:

The panel considers the post-mastectomy hypofractionated RT of solely the thoracic wall with NO immediate breast reconstruction to be safe.

\begin{tabular}{|l|l|}
\hline Level of agreement & Level of evidence \\
\hline $100 \%$ & Moderate \\
\hline
\end{tabular}

Comments: Despite Start studies $\left(\mathrm{A}^{13}\right.$ and $\left.\mathrm{B}^{12}\right)$ not having as the assessment of post-mastectomy hypofractionated RT as the initial objective, this group represented 8\% (513 patients) of the sample ${ }^{3}$. There was no statistical power for a recommendation. However, locoregional recurrence happened in $6.8 \%$ of these patients. The toxicity was not different for patients who underwent mastectomy and hypofractionated $\mathrm{RT}^{3}$. Radiobiological ratios of similar remaining-tissue sensibility, regardless of the surgical technique, and the potential reduction of late events from breast $\alpha / \beta$ encourage the use of hypofractionated models ${ }^{14}$.

There was NO agreement as to the safety of the indication of post-mastectomy hypofractionated RT after immediate breast reconstruction WITH prosthesis/tissue expander.

\begin{tabular}{|l|l|}
\hline Level of agreement & Level of evidence \\
\hline $28 \%$ & Weak \\
\hline
\end{tabular}

Comments: The Start studies $\left(\mathrm{A}^{13}\right.$ and $\left.\mathrm{B}^{12}\right)$ excluded post-mastectomy patients with immediate reconstruction, and there are no other studies that can be used as a reference for the procedure.

There was NO agreement as to the safety of the indication of post-mastectomy hypofractionated RT after immediate breast reconstruction WITH autologous tissue.

\begin{tabular}{|l|l|}
\hline Level of agreement & Level of evidence \\
\hline $39 \%$ & Weak \\
\hline
\end{tabular}

Comments: The Start studies $\left(\mathrm{A}^{13}\right.$ and $\left.\mathrm{B}^{12}\right)$ excluded post-mastectomy patients with immediate reconstruction and, to the present day, there are no other studies with results that can be used as a reference for the procedure.

The panel considers the treatment with hypofractionated RT to be safe for breasts of all sizes, as long as the recommended technical criteria presented in this document are followed. 
Level of agreement

$100 \%$

Level of evidence

Strong

Comments: The Start studies $\left(\mathrm{P}^{15}, \mathrm{~A}^{13}\right.$, and $\left.\mathrm{B}^{12}\right)$ did not limit breast size, and classified them into small, medium, and large. There was no toxicity difference amongst different breast sizes. The restriction should be made according to dosimetric parameters $^{3}$. The Canadian study ${ }^{4}$ limited the inclusion of breasts with latero-lateral diameter above $25 \mathrm{~cm}^{2}$. This panel strongly suggests the use of the technical parameters established in Section III - Safety in the hypofractionated RT technology applied to treat breast cancer.

\section{CHEMOTHERAPY}

The panel considers the treatment of exclusively the breast with hypofractionated RT, AFTER adjuvant CT, to be safe.

\begin{tabular}{|l|l|}
\hline Level of agreement & Level of evidence \\
\hline $100 \%$ & Strong \\
\hline
\end{tabular}

Comments: Several randomized clinical trials allowed CT patients in their adjuvant treatment protocols. Adjuvant CT was used in $13.9 \%, 35.5 \%, 22.2 \%$, and $11 \%$ in the Start- ${ }^{15}$, Start $\mathrm{A}^{13}$, Start ${ }^{12}$ and Cana$\operatorname{dian}^{4}$ studies, respectively. In addition, in the Cochrane meta-analysis ${ }^{16}, 1,728$ patients $(21 \%)$ received adjuvant CT.

There was no difference in local control in the Start $\left(\mathrm{P}^{15}, \mathrm{~A}^{13}\right.$, and $\left.\mathrm{B}^{12}\right)$ and Canadian ${ }^{4}$ studies in the subgroup of adjuvant CT, regardless of the RT model used (hypofractionated RT or conventional RT). Similarly, upon evaluating cosmesis and regular tissue toxicity, there was no difference amongst the study groups, regardless of the the use of adjuvant CT. The use of hypofractionated RT for breast cancer has been increasing considerably over the years.

A study conducted by the US National Cancer Database showed an increase in hypofractionated RT indication for patients who received CT, with an absolute increase of $13.6 \%$ over the last decade (from $4.6 \%$ to $18.2 \%)^{17}$.

The panel considers the treatment of exclusively the breast with hypofractionated RT, AFTER neoadjuvant CT, to be safe.

\begin{tabular}{|l|l|}
\hline Level of agreement & Level of evidence \\
\hline $94 \%$ & Weak \\
\hline
\end{tabular}

Comments: None of the clinical trials that assessed hypofractionated RT included neoadjuvant $\mathrm{CT}$ in their respective treatment protocols ${ }^{\mathbf{1 6}}$; however, the indication in this scenario has substantially increased over the last few years ${ }^{16,17}$.

Randomized prospective studies are being conducted with indications and models of hypofractionated RT posterior to neoadjuvant CT. In current clinical practice, the exposure to CT, both adjuvant as neoadjuvant, prior to surgery did not alter the toxicity patterns for hypofractionated RT.

The panel does NOT consider to be safe the treatment of exclusively the breast with hypofractionated $R T$ and concurrent CT.

\begin{tabular}{|l|l|}
\hline Level of agreement & Level of evidence \\
\hline $100 \%$ & Weak \\
\hline
\end{tabular}

Comments: The is no data in the literature that addresses the oncologic safety of hypofractionated RT concurrent with CT since the main clinical trials available did not use that combination ${ }^{17}$.

The panel considers the treatment of exclusively the breast with hypofractionated RT, exclusively concurrent with anti-HER2 drugs, to be safe.

\begin{tabular}{|l|l|}
\hline Level of agreement & Level of evidence \\
\hline $89 \%$ & Weak \\
\hline
\end{tabular}

Comments: Trastuzumab, as well as other anti-HER2 drugs, were not clinically assessable during recruiting for breast hypofractionated RT. Trastuzumab can be safely used after and concurrent with conventional RT. In a mitigating scenario, trastuzumab was administered with hypofractionated RT in several clinical situations, and no increased toxicity was observed ${ }^{17}$.

\section{DCIS}

The panel considers the treatment of exclusively the breast with hypofractionated RT to be safe in patients with pure Ductal Carcinoma IN SITU.

\begin{tabular}{|l|l|}
\hline Level of agreement & Level of evidence \\
\hline $100 \%$ & Moderate \\
\hline
\end{tabular}

Comments: In a meta-analysis of breast hypofractionated RT conducted by Cochrane ${ }^{16}$, only $0.15 \%$ of patients presented a diagnosis of pure DCIS, and there was no evidence of a difference in local con- 
trol and toxicity. The retrospective Montreal study showed similarities in the relapse patterns for the ipsilateral breast with the hypofractionated models for the pure DCIS histology ${ }^{18}$

\section{AGE}

The panel considers the treatment of exclusively the breast with hypofractionated RT to be safe in patients between 40 and 50 years old.

\begin{tabular}{|l|l|}
\hline Level of agreement & Level of evidence \\
\hline $100 \%$ & Strong \\
\hline
\end{tabular}

Comments: The Start $\mathrm{A}^{13}$, Start $\mathrm{B}^{12}$ and Canadian ${ }^{4}$ studies included, respectively, $23 \%, 21 \%$, and $25 \%$ of women under 50 years old. The local control was similar among different ages.

There was NO agreement regarding the safety of indication of hypofractionated RT of exclusively the breast for patients with age under 40 years.

\begin{tabular}{|l|l|}
\hline Level of agreement & Level of evidence \\
\hline $61 \%$ & Strong \\
\hline
\end{tabular}

Comments: The Start studies $\left(\mathrm{P}^{15}, \mathrm{~A}^{13}\right.$, and $\left.\mathrm{B}^{12}\right)$ included only $5.8 \%$ women under 40 years old. The local control and toxicity of normal tissue presented similar results among groups; however, without the due safety of indication to this day.

\section{DRAINAGE}

There was NO agreement regarding the safety of indication of hypofractionated RT exclusively of the breast in lymphatic drainage of the supraclavicular fos$s a(\mathrm{SCF})$.

\begin{tabular}{|l|l|}
\hline Level of agreement & Level of evidence \\
\hline $56 \%$ & Moderate \\
\hline
\end{tabular}

Comments: The Start studies $\left(\mathrm{P}^{15}, \mathrm{~A}^{13}\right.$, and $\left.\mathrm{B}^{12}\right)$ used hypofractionated RT in the SCF, respectively, in $20 \%, 14 \%$, and $7 \%$ of a total of 470 patients. The Cochrane ${ }^{16}$ meta-analysis grouped only $10 \%$ of patients who underwent hypofractionated RT in the SCF. The Canadian ${ }^{4}$ study did not include patients for lymphatic drainage irradiation.

A Chinese ${ }^{19}$ study randomized 811 patients with high-risk breast cancer, stage II, for conventional or hypofractionated RT in the SCF and did not observe any difference in locoregional recurrence, distant metasta- sis, disease free survival, and global survival. Locoregional recurrence was also similar in meta-analysis ${ }^{20}$ [relative risk $[\mathrm{RR}]=1.03 ; 95 \% \mathrm{CI}(0.87 ; 1.23), \mathrm{P}=0.72$ ], and in the Start ${ }^{14}$ studies (0.5\% vs $0.3 \%$; $\left.=0.71\right)$. The risks of pulmonary toxicity, rib fracture, plexopathy, and upper limb lymphedema were similar between the conventional and hypofractionated RT models ${ }^{14,20}$.

There was NO agreement regarding the safety of indication of hypofractionated RT exclusively of the breast in lymphatic drainage of the supraclavicular fossa (SCF) and axilla.

\begin{tabular}{|l|l|}
\hline Level of agreement & Level of evidence \\
\hline $33 \%$ & Weak \\
\hline
\end{tabular}

Comments: There were no randomized clinical trials that included the axilla in RT volumes. Despite some studies suggesting the model were equivalent regarding acute and late toxicities, most panel members did not consider hypofractionated radiotherapy to be appropriate in this context due to a lack of safety for recommendation to this day.

There was NO agreement regarding the safety of indication of hypofractionated RT exclusively of the breast in lymphatic drainage of the internal mammary chain.

\begin{tabular}{|l|l|}
\hline Level of agreement & Level of evidence \\
\hline $22 \%$ & Weak \\
\hline
\end{tabular}

Comments: The randomized studies did not include the internal mammary chain in the RT volumes. Despite some studies suggesting equivalent levels of acute and late toxicity, it is not possible to exclude the possibility of increased pulmonary, costal arch, and heart toxicity with hypofractionated radiotherapy due to lack of scientific evidence ${ }^{20}$.

\section{BOOST}

The panel considered the administration of a boost in patients who undergo breast hypofractionated RT to be safe.

\begin{tabular}{|l|l|}
\hline Level of agreement & Level of evidence \\
\hline $100 \%$ & Strong \\
\hline
\end{tabular}

Comments: The use of a boost during surgery, when indicated, was used in different randomized controlled trials. In the Start studies $\left(\mathrm{P}^{15}, \mathrm{~A}^{13}\right.$, and $\left.\mathrm{B}^{12}\right)$ and the Cochrane ${ }^{16}$ meta-analysis compilation, a boost 
was used in $75 \%, 60 \%, 43 \%$, and $44 \%$ of patients, respectively. In MD Anderson ${ }^{21}$ and a Chinese ${ }^{22}$ study, all patients had a boost after the whole-breast hypofractionated RT. No increased toxicity was observed with the addition of a boost to the hypofractionated models when compared to conventional therapy ${ }^{16,20,22}$.

The models used were: $3 x 3$ Gy, 4x2,5 Gy, 3x2,67 Gy and 5x2 Gy.

\section{T3 STAGE}

The panel considered the use of breast hypofractionated RT to be safe in patients with T3 tumors.

\begin{tabular}{|l|l|}
\hline Level of agreement & Level of evidence \\
\hline $77 \%$ & Weak \\
\hline
\end{tabular}

Comments: The T3 stage was included in the Start studies $\left(\mathrm{P}^{15}, \mathrm{~A}^{13}\right.$, and $\left.\mathrm{B}^{12}\right)$, with tumors equal or larger than T2 representing $42.5 \%, 48.6 \%$, and $35.9 \%$, respectively. There is no analysis of the results; however, the randomized controlled trials considered that the size of the resected tumor, on its own, should not be an exclusion factor for hypofractionated radiotherapy ${ }^{14}$.

\section{GRADE III HISTOLOGY}

The panel considered the use of breast hypofractionated RT to be safe in patients with grade-III-histology tumors.

\begin{tabular}{|l|l|}
\hline Level of agreement & Level of evidence \\
\hline $100 \%$ & Strong \\
\hline
\end{tabular}

Comments: The compilation of the Start ${ }^{3}$ studies showed that the tumor grade was not an isolated prognostic factor. Amongst the 5,861 patients grouped in the Start studies $\left(\mathrm{P}^{15}, \mathrm{~A}^{13}\right.$, and $\left.\mathrm{B}^{12}\right)$, it was observed $9 \%$ of locoregional recurrence for tumors with grade III histology, and $4.5 \%$ and $3.4 \%$, respectively, for grade II and I. In the subgroup analysis of the Canadian ${ }^{4}$ study, grade III histology was a risk factor linked to an increase in local recurrence. However, regardless of histological grade, those patients who underwent hypofractionated RT did not present an increase in relapse when compared with conventional RT. A specific population cohort study with grade II patients who underwent hypofractionated RT also did not show evidence of increased risk of locoregional recurrence in early-stage breast cancer ${ }^{23}$.

The summary of accepted considerations that are recommended by the panel members with over $75 \%$ of agreement is presented in Table 1.

\section{SECTION III - SAFETY IN THE HYPOFRACTIONATED RT TECHNOLOGY APPLIED TO TREAT BREAST CANCER}

This panel of specialists recommends, for the breast hypofractionated RT, the use of the three-dimensional conformal technique (3DCRT). This technique uses dedicated computer tomography, with which it is possible to assess the distribution of the radiation dose in the target volume and the adjacent organs at risk (OARs), providing increased quality and safety during the treatment.

TABLE 1. PROFILE OF PATIENT FOR WHICH THE SBRT CONSENSUS RECOMMENDS THE USE OF HYPOFRACTIONATED RT FOR BREAST CANCER TREATMENT (AGREEMENT > 75\% AMONGST PANEL MEMBERS)

\begin{tabular}{l|l|l} 
Variable & $\begin{array}{l}\text { Level of } \\
\text { agreement (\%) }\end{array}$ & Level of evidence \\
\hline $\begin{array}{l}\text { Surgery } \\
\text { Conservative }\end{array}$ & 100 & Strong \\
\hline Mastectomy & & \\
\hline Without reconstruction & 100 & Moderate
\end{tabular}

\begin{tabular}{l|l|l} 
Age & & \\
\hline$>40$ years & 100 & Strong \\
\hline
\end{tabular}

\begin{tabular}{l|l|l} 
Stage of the tumor & & \\
\hline $\mathrm{T} 1-\mathrm{T} 2$ & 100 & Strong \\
\hline $\mathrm{T} 3$ & 77 & Weak \\
\hline
\end{tabular}

\begin{tabular}{l|l|l} 
Histological grade & & \\
\hline G1 - G2 - G3 & 100 & Strong \\
\hline
\end{tabular}

\begin{tabular}{l|l|l} 
Histology & & \\
\hline $\begin{array}{l}\text { Invasive carcinoma of no } \\
\text { special type }\end{array}$ & 100 & Strong \\
\hline DCIS & 100 & Moderate \\
\hline Regardless of IHC & 100 & Strong \\
\hline
\end{tabular}

\begin{tabular}{l|l|l} 
Axillary lymph nodes & & \\
\hline Absent & 100 & Strong \\
\hline
\end{tabular}

\begin{tabular}{l|l|l} 
Breast size & & \\
\hline Any size & 100 & Strong \\
\hline
\end{tabular}

\begin{tabular}{l|l|l} 
Systemic treatment & \multicolumn{2}{|l}{} \\
\hline After adjuvant CT & 100 & Strong \\
\hline After neoadjuvant CT & 94 & Weak \\
\hline $\begin{array}{l}\text { Concurrent with an- } \\
\text { ti-HER2 drugs }\end{array}$ & 89 & Weak \\
\hline \multicolumn{2}{|l}{} \\
\hline Boost & 100 & Strong \\
\hline
\end{tabular}

DCIS = Ductal Carcinoma IN SITU. IHC = Immunohistochemical. CT = Chemotherapy. $\mathrm{RT}=$ Radiotherapy 
The panel members suggest complying with the following criteria:

- Image acquisition and treatment in the supine position;

- Use of proper restraining devices that allows the patient to be comfortable and the position to be reproduced;

- The delineation of target structures and OARs as recommended by breast cancer contouring atlas by the RTOG ${ }^{24}$ (https://www.rtog.org/ CoreLab/ContouringAtlases/BreastCancerAtlas.aspx) or the $\mathrm{ESTRO}^{21}$ (https://www.ncbi. nlm.nih.gov/pubmed/25630428).

- Evaluation of the dose-volume histogram (DVH); the constraints and prescription doses according to the RTOG $1005^{25}$ are suggested by this panel.

- PTV_Eval - Breast CTV + 5-10 mm margin for setup, editing $5 \mathrm{~mm}$ of skin and excluding the volume of the costal arches.

- D95\%=95\% in an optimal scenario, being acceptable up to D90\%=90\%;

TABLE 2. DOSE-VOLUME CONSTRAINTS FOR PLANNING WHOLE-BREAST HYPOFRACTIONATED RADIOTHERAPY, ACCORDING TO THE RTOG $1005^{25}$ CRITERIA

\begin{tabular}{l|l} 
Structure & Criteria \\
\hline Breast CTV & D95\% $\geq 38(\geq 36) \mathrm{Gy}$ \\
& D50\% $\leq 43.2(\leq 44.8) \mathrm{Gy}$ \\
\hline Boost CTV & D95\% $\geq 9.5(9.0) \mathrm{Gy}$ \\
& V11Gy $\leq 5(10) \%$ \\
\hline Heart & V16(20)Gy $\leq 5 \%$ \\
& V8Gy $\leq 30(35) \%$ \\
& MeanD $\leq 3.2(4) \mathrm{Gy}$ \\
\hline Lung & V16Gy $\leq 15(20) \%$ \\
& V8Gy $\leq 35(40) \%$ \\
\hline Contralateral lung - IMRT & V4Gy $\leq 50(55) \%$ \\
\hline Contralateral breast & V4Gy $\leq 10(15) \%$ \\
\hline
\end{tabular}

$\mathrm{CTV}=$ clinical tumor volume, IMRT = Intensity-modulated radiotherapy, $\mathrm{D}=$ dose that receives the $\%$ the volume, $V_{G y}=$ volume that receives the dose in Gy, MeanD = mean dose, $\operatorname{MaxD}=$ maximum dose
- DMAX $=115 \%$ in an optimal scenario, being acceptable up to $120 \%$;

- Compliance index (CI): volume covered by $95 \%$ of the prescription isodose/ PTV_Eval volume, this being from 0.95-2 (optimal) and the acceptable value of 0.85-2.5;

OARs constraints, such as ipsilateral lung, heart, contralateral lung, thyroid, and contralateral breast, according to the RTOG 1005 - Annex IV - p. $83^{25}$.

(https://www.rtog.org/clinicaltrials/protocoltable/ studydetails.aspx action $=$ openFile \&FileID $=9366$ rtog 1005 protocol) (Table 2);

- It is recommended to always use a linear accelerator;

- It is recommended to confirm the positioning with, at least, planar imaging on the first day of treatment and weekly, according to the RDC20 26 .

\section{FINAL CONSIDERATIONS}

These recommendations presented by the SBRT for the use of whole-breast hypofractionated radiotherapy will aid Brazilian radiotherapy experts regarding indications and particularities of this technique as a viable and safe alternative for the national reality.

\section{ACKNOWLEDGMENTS}

The SBRT thanks the Silicon Valley Community Foundation, through the Varian Medical Systems, for their financial support in part used to the holding of the consensus meeting that took place in March 3rd, 2018 in the city of São Paulo.

The SBRT thanks the ABFM and the SBM for their continuous and solid partnership. We also thank our secretary assistants, Misses Rafaela Bernardo, Eliane Alves, and Vanessa Carvalho, for their hard work and dedication.

\section{RESUMO}

Este consenso de recomendações para a radioterapia (RT) hipofracionada de toda a mama foi organizado pela Sociedade Brasileira de Radioterapia (SBRT) considerando o cenário ideal para indicação e segurança na tecnologia aplicada. Questões de controvérsias e contraindicações (RT hipofracionada em pacientes submetidas à quimioterapia [QT], RT hipofracionada nas drenagens linfáticas, $R T$ hipofracionada após mastectomia com ou sem reconstrução imediata, a realização de reforço de dose em leito cirúrgico [ou boost], $R T$ hipofracionada em pacientes com idade menor que 50 anos, RT hipofracionada em mamas volumosas, RT hipofracionada em histologia de carcinoma in situ [CDIS]) foram discutidas em encontro presencial, sendo o consenso atingido quando existisse concordância de pelo menos 75\% dos panelistas. O grau de recomendação foi também sugerido de acordo com o nível de evidência científico disponível, qualificado entre fraco, médio ou forte. Assim, este consenso deverá servir para auxiliar os especialistas da radioterapia brasileira em relação às indicações e particularidades dessa técnica, como uma alternativa segura e viável para a realidade nacional. 


\section{REFERENCES}

1. MINISTÉRIO DA SAÚDE, Instituto Nacional de Câncer José Alencar Gomes da Silva. Estimativa 2018-Incidência de Câncer No Brasil.; 2017.

2. Early Breast Cancer Trialists' Collaborative Group (EBCTCG), Darby S, McGale P, et al. Effect of radiotherapy after breast-conserving surgery on 10-year recurrence and 15-year breast cancer death: meta-analysis of individual patient data for 10801 women in 17 randomised trials. Lancet. 2011;378(9804):1707-1716. doi:10.1016/S0140-6736(11)61629-2.

3. Haviland IS, Owen IR, Dewar |A, et al. The UK Standardisation of Breast Radiotherapy (START) trials of radiotherapy hypofractionation for treatment of early breast cancer: 10-year follow-up results of two randomised controlled trials. Lancet Oncol. 2013;14(11):1086-1094. doi:10.1016/S14702045(13)70386-3.

4. Whelan TJ, Pignol J-P, Levine MN, et al. Long-Term Results of Hypofractionated Radiation Therapy for Breast Cancer. N Engl / Med. 2010;362(6):513-520. doi:10.1056/NEJMoa0906260.

5. Smith $B D$, Bentzen $S M$, Correa $C R$, et al. Fractionation for Whole Breast Irradiation: An American Society for Radiation Oncology (ASTRO) Evidence-Based Guideline. Int / Radiat Oncol. 2011;81(1):59-68. doi:10.1016/j. ijrobp.2010.04.042.

6. Smith BD, Bellon JR, Blitzblau R, et al. Radiation therapy for the whole breast: Executive summary of an American Society for Radiation Oncology (ASTRO) evidence-based guideline. Pract Radiat Oncol. 2018;8(3):145152. doi:10.1016/j.prro.2018.01.012

7. Moraes FY de, Marta GN, Hanna SA, et al. Brazil's Challenges and Opportunities. Int / Radiat Oncol. 2015;92(4):707-712. doi:10.1016/j. ijrobp.2014.12.063

8. Weltman E, Marta GN, Weltman E, Marta GN. Radiotherapy and the SUS: A collapse foretold. Rev Assoc Med Bras. 2017;63(2):93-94. doi:10.1590/1806-9282.63.02.93.

9. BRASIL. Tribunal de Contas da União (TCU). Política Nacional de Atenção Oncológica. Brasília: TCU, Secretaria de Fiscalização e Avaliação de Programas de Governo; 2011.

10. Andrews |, Guyatt G, Oxman AD, et al. GRADE guidelines: 14. Going from evidence to recommendations: the significance and presentation of recommendations. / Clin Epidemiol. 2013;66(7):719-725. doi:10.1016/j.jclinepi.2012.03.013

11. Sinha IP, Smyth RL, Williamson PR. Using the Delphi Technique to Determine Which Outcomes to Measure in Clinical Trials: Recommendations for the Future Based on a Systematic Review of Existing Studies. PLoS Med. 2011;8(1):e1000393. doi:10.1371/journal.pmed.1000393.

12. START Trialists' Group, Bentzen SM, Agrawal RK, et al. The UK Standardisation of Breast Radiotherapy (START) Trial B of radiotherapy hypofractionation for treatment of early breast cancer: a randomised trial. Lancet. 2008;371(9618):1098-1107. doi:10.1016/S0140-6736(08)60348-7.

13. START Trialists' Group, Bentzen SM, Agrawal RK, et al. The UK Standardisation of Breast Radiotherapy (START) Trial A of radiotherapy hypofractionation for treatment of early breast cancer: a randomised trial. Lancet Oncol. 2008;9(4):331-341. doi:10.1016/S1470-2045(08)70077-9.
14. Yarnold J. Changes in radiotherapy fractionation-breast cancer. Br J Radiol. March 2018:20170849. doi:10.1259/bjr.20170849.

15. Yarnold J, Ashton A, Bliss J, et al. Fractionation sensitivity and dose response of late adverse effects in the breast after radiotherapy for early breast cancer: long-term results of a randomised trial. Radiother Oncol. 2005;75(1):9-17. doi:10.1016/j.radonc.2005.01.005.

16. Hickey BE, James ML, Lehman M, et al. Hypofractionated radiation therapy for early breast cancer. Cochrane Database Syst Rev. 2016;7:CD003860. doi:10.1002/14651858.CD003860.pub4.

17. Diwanji TP, Molitoris JK, Chhabra AM, et al. Utilization of hypofractionated whole-breast radiation therapy in patients receiving chemotherapy: a $\mathrm{Na}$ tional Cancer Database analysis. Breast Cancer Res Treat. 2017;165(2):445453. doi:10.1007/s10549-017-4345-y.

18. Williamson D, Dinniwell R, Fung S, Pintilie M, Done SI, Fyles AW. Local control with conventional and hypofractionated adjuvant radiotherapy after breast-conserving surgery for ductal carcinoma in-situ. Radiother Oncol. 2010;95(3):317-320. doi:10.1016/j.radonc.2010.03.021.

19. Sun GY, Wang SL, Song YW, et al. Hypofractionated Radiation Therapy After Mastectomy for the Treatment of High-Risk Breast Cancer: 5-Year Follow-Up Result of a Randomized Trial. Int | Radiat Oncol. 2017;99(2):S3S4. doi:10.1016/J.IJROBP.2017.06.024.

20. Zhou Z-R, Mei $X$, Chen $X-X$, et al. Systematic review and meta-analysis comparing hypofractionated with conventional fraction radiotherapy in treatment of early breast cancer. Surg Oncol. 2015;24(3):200-211. doi:10.1016/j.suronc.2015.06.005.

21. Shaitelman SF, Schlembach PI, Arzu I, et al. Acute and Short-term Toxic Effects of Conventionally Fractionated vs Hypofractionated WholeBreast Irradiation. JAMA Oncol. 2015;1(7):931. doi:10.1001/jamaoncol.2015.2666

22. Zhao S, Liu Y, Huang F, Chen $X$, Cao X, Yu J. The long-term outcome of adjuvant hypofractionated radiotherapy and conventional fractionated radiotherapy after breast-conserving surgery for early breast cancer: a prospective analysis of 107 cases. J Thorac Dis. 2017;9(10):3840-3850. doi:10.21037/jtd.2017.09.125

23. Herbert $C$, Nichol A, Olivotto I, et al. The Impact of Hypofractionated Whole Breast Radiotherapy on Local Relapse in Patients With Grade 3 Early Breast Cancer: A Population-Based Cohort Study. Int / Radiat Oncol. 2012;82(5):2086-2092. doi:10.1016/j.jirobp.2011.01.055.

24. White I, Tai A, Arthur D, et al. Breast Cancer Atlas for Radiation Therapy Planning: RTOG Consensus Definitions. https://www.rtog.org/LinkClick. aspx?fileticket=vzJFhPaBipE\%3D\&tabid=236. Accessed April 7, 2018.

25. Arbor A, Freedman GM, Arthur DW. A Phase III Trial of Accelerated Whole Breast Irradiation with Hypofractionation Plus Concurrent Boost Versus Standard Whole Breast Irradiation Plus Sequential Boost For Early-Stage Breast Cancer. Radiat Ther Oncol Gr RTOG 1005. 2013:1-86.

26. ANVISA - Diretoria Colegiada da Agência Nacional de Vigilância Sanitária. RESOLUÇÃO-RDC No 20, DE 5 DE MAIO DE 2011. http://www.anvisa.gov. br/sngpc/Documentos2012/RDC 20 2011.pdf. Accessed June 3, 2018. 